\title{
Erratum to: Development of a nomogram combining clinical staging with 18F-FDG PET/CT image features in non-small-cell lung cancer stage I-III
}

Marie-Charlotte Desseroit $^{1,2} \cdot$ Dimitris Visvikis $^{2} \cdot$ Florent Tixier $^{1,3}$.

Mohamed Majdoub $^{2}$ - Rémy Perdrisot ${ }^{1,3}$ - Rémy Guillevin ${ }^{3,4}$.

Catherine Cheze Le Rest ${ }^{1,3}$ - Mathieu Hatt ${ }^{2}$

Published online: 21 June 2016

(C) Springer-Verlag Berlin Heidelberg 2016

Erratum to: European Journal of Nuclear Medicine and Molecular Imaging

DOI 10.1007/s00259-016-3325-5

This work received the support of the National Institute of Cancer (INCa project \#C14020NS).

The online version of the original article can be found at http:// dx.doi.org/10.1007/s00259-016-3325-5.

Marie-Charlotte Desseroit

Marie-Charlotte.Desseroit@univ-brest.fr

1 Nuclear Medicine, University Hospital, Poitiers, France

2 INSERM, UMR 1101, LaTIM, CHRU Morvan, University of Brest, 2 avenue Foch, 9609 Brest, France

3 Medical School, EE DACTIM, University of Poitiers, Poitiers, France

4 Radiology, University Hospital, Poitiers, France 